\title{
Investigation of Radio Frequency Emissivity Effect on Human Cells
}

\author{
Mohd Zafran Abdul Aziz, Syed Farid Syed Adnan and Rohaiza Yusoff \\ Faculty Of Electrical Engineering,Universiti Teknologi MARA \\ Shah Alam,Selangor, Malaysia \\ zafran@salam.uitm.edu.my
}

\begin{abstract}
This paper reviews some papers discussing the effect of radio frequency (RF) on human cells and proposal toward better experimental work. A prototype of radio frequency absorber box with air ventilation was introduced in order to investigate its effect on human cells. A few factors that contribute to the effect of radiation is recognized and studied. The success of our proposed iron mesh box to absorb RF signals was demonstrated wherein normal level of $R F$ radiation is achieved within the closed system of the incubator. The mesh box has been shown to have absorbed at least $88.11 \%$ of total RF generated.
\end{abstract}

Keywords- Radio Frequency, Human, Health

\section{INTRODUCTION}

As the technology grows, the use of various wireless communication methods has increased. The awareness of the effect on radio frequency wave is crucial for everybody so that the flexibility of using the technologies provide greater benefits over the adverse effects on human health. Wireless communication is needed for several applications but the RF channel propagation of the signals in different bandwidth and environment must be proven safe and harmless to other systems including human body.

In this paper, a few wireless technology characteristics are discussed for average daily usage. Two categories are observed; which are active and passive users. Active user is someone who is act ively using a ny portable wireless technology devices while a passive user is someone who is not using that $\mathrm{p}$ articular wireless technolo gy but was present in the area which was occupied by certain wireless facilities. Fig. $1 \mathrm{~s}$ hows data rate of common wireless facilities with range capability.

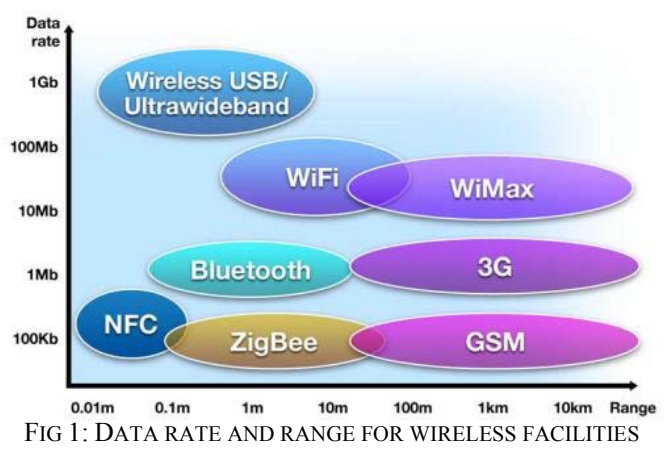

The use of RF and microwaves technologies in health and medicine has increased dramatically over the last ten years. RF and microwave therapies for the treatment of cancer in humans are well documented, and are presently used in many cancer centres. New modalities are being studied and focused on R F and microwave application. The enhancement of technology in d rug absorption and microwave septic wound treatment, microwave imaging for the detection of breast cancer, epidemiological studies on the effects of rats' exposure to microwave, and al so tissue regeneration using electromagnetic fields. Presently, the technology is being developed which allows for permanent implantation of microwave wireless sensors in humans [1]. A permanently implantable intra-cranial pressure monitor is one of the applications with the latter technology approach.

There are specific test guidelines introduced in order to prove the result obtained, and to ensure the saf ety of subject under study.

\section{A. Test Guidelines}

The guidelines of RF ex posure and radiation have been promulgated for nearly half a century. However, the understanding of biological effects of exposure to RF radiation is still evolving and more so for cellular mobile telephones and wireless personal communication devices [2]. The maximum power deposition which measured in specific absorption rate of RF energy-SAR allowed varies between $1.6 \mathrm{~W} / \mathrm{kg}$ in $1 \mathrm{~g}$ and $2 \mathrm{~W} / \mathrm{kg}$ in any $10 \mathrm{~g}$ of tissue in the head, from exposure to cellular telephone wireless radiation.

The standard of guidelines for maximum permissible levels of exposure to RF and microwave radiation is a valid approach to managing the risk of such exposures. Meanwhile the existing guidelines, are based o $n$ results obtained from acute, short-term studies that are atypical of the RF exposures associated with the handset of cellular mobile telephones.

A SAR test methodology has been developed by [3] in order to provide safety assessment for the two $\mathrm{WNaN}$ antennas in the range of 900 to $6000 \mathrm{MHz}$ frequency band. For the extreme wide band operating frequency, three sub-bands have been devised to minimize uncertainty from the measurements caused by the deviation of the permittivity and conductivity from the target $\mathrm{v}$ alues. A software tool has been developed to adopt error correction 
and dielectric parameters prediction algorithms. A numerical solution using finite-difference timedomain (FDTD) modelling is also develo ped to evaluate the SAR measurements.

\section{RELATED WORKS}

A few works done by other researchers are discussed and will be divided into two subtopics. First subtopic is works indicating that RF radiation is bad for human health and second subtopic is works indicating negligible effects of RF on human health. Before any statement is be ing judge, few of parameters should be considered.

\section{A. Works indicating that $R F$ radiation is bad for human health}

Radio Frequency (RF) radiation effects are strictly relying on few critical factors such as frequency, period of exposure and distance. Certain frequency ranges are absorbed in body tissue more than the other frequency range. The second factor is the duration of exposure. Where, over the period of time, the body will absorb more RF frequencies which hence will worsen the human tissue The third factor is the distance of radiating elements from the human body. Hence, with respect to that unawareness of human towards the effects of the RF exposure, the study conducted by [4] simulated the base station radiation effects on human health.

The experiments was conducted using mice as it has the closest DNA structure to human and the frequency used in the experiments was $1.8 \mathrm{GHz}$ [5]. The mice were exposed at $1.8 \mathrm{GHz}$ frequency, certain level of intensity and over a period of time. Second test conducted was the histopathology to examine the tissue of the mice out from the autopsy. The third test was the blood count on red blood cells, white blood cells, hemoglobin and packed cell volume. From the tests which are conducted at veterinary Lab, there are evidences of degeneration of cells in some organs through histop athological procedures. While in through biochemistry test, the level of blood calcium and phosphorus were dec reasing and the level of blood creatinine was increasing. All this evidences show that, exposure to certain level of frequencies will affect human body.

The group had proceeded to invest igating WiFi frequency of $2.4 \mathrm{GHz}$ [6]. The radiation was exposed to mice continuously everyday for 8 hours and for 6 months period. The research is conducted on a laboratory with a few cages consists of 30 male mice and they were placed at a far-field distance of $1.0 \mathrm{~m}$ from the antenna of the RF generator source. Another cage control which consists of 30 male mice was place d far away from radiation area, almost under free-radiation. The results were categorized into three tests that are Pathology Lab, Blood Count and Biochemistry Lab. From the tests, it has been shown that the degeneration occurs in the cell $\mathrm{s}$ on some organs through histopathological procedures.

In [7] they strongly claim that the exposure to RF radiation has some biological effects to the 1 aboratory mice as well as human being, as th ey have some similarities in biological characteristics.

Li Yang et al in [8] simulated the RF fields focused on the eye cells model and the ey es with glasses of metal frame respectively. A planar inverted $\mathrm{F}$ antenna is used as an exposure source at $900 \mathrm{MHz}$. Under this case, the intensity of the electrical field is calculated and analysed. Also, SAR is u tilized to evaluate the absorption of the organs to the radiation. Through the simulation, the peak values of SAR per $1 \mathrm{G}$ tissue at the radiating power being $600 \mathrm{~mW}$ are o btained. It is concl uded that when people wear glasses of metal framework, the peak value of SAR is shown to be a little higher than the safety limits. It is suggested that the radiation from the mobile handset do more harm to the ey es of wearers glasses of metal frameworks.

\section{B. Works indicating negligible effects of RF on human health}

The National Council on Radiation Protection published a two-tiered approach to exposure standards for several reasons. First, individuals exposed in the work place are generally informed of the potential hazards of the exposure and can decide to limit that exposure if desired. Such knowledge cannot be ex pected of th e general population. Second, the general po pulation contains individuals who may be rehabilitated in some manner and for whom occupational exposure levels may present undue risk. Lastly, the general population is much larger than the work population, and thus the number of people at risk is corr espondingly larger. Consequently, a meaningful reduction in exposure levels is i ndicated in order to ensure proportionate risk levels for occupational nonoccupational environment.

Stephen in [9] said t hat there is no s upportable evidence to show that radiation from cellular telephones causes adverse health effects. Therefore, the more intelligent yet effective approaches must be carried out for the sake of human safety

The two situations above shows that RF signals could give either bad effect or no effect at all to human health. In this work, a few criteria and parameters are counted in order to have more specific procedures especially for passive and active users.

\section{METHODLOGY}

In this res earch, animal culture cells are used t o represent a life cell. These cells will be radiated with radio frequency with certain levels of power with variety of frequency. A signal generator was used to generate the RF signal and measurement of receiving power 1 evel was captured by spectrum analyzer. A directional antenna was used to radiate the cells in a special iron mesh box size (9.25" x $\left.5 " \times 5.5^{\prime \prime}\right)$. This box has the capability to absorb the RF signal to make sure there is no radiation effect outside the box. The box is placed in an incubator to make 
sure the cells alive. The diagram in Fig. 2 below shows the arrangement of experiment. The control experiment is placed in incubator without the radiation. The para meter of each device used is tabulated in Table 1.

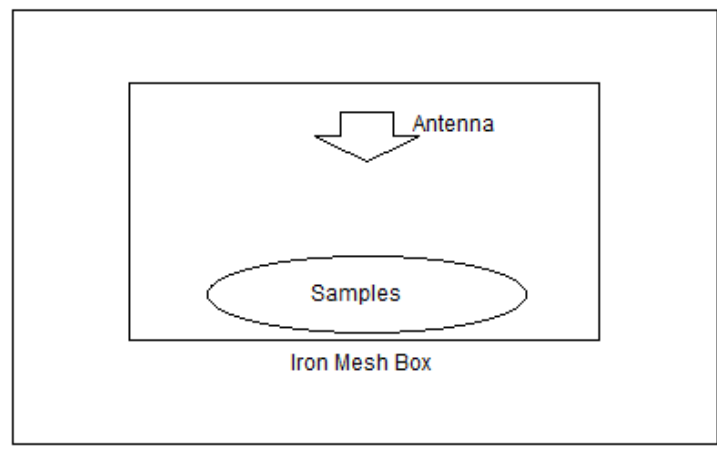

Incubator

FIG. 2: BLOCK DIAGRAM OF EXPERIMENT SET UP

TABLE 1: PARAMETER USED IN EXPERIMENT

\begin{tabular}{|l|l|}
\hline Parameter & Value \\
\hline Frequency Used & $900 \mathrm{MHz}, 1800 \mathrm{MHz}, 2.4 \mathrm{GHz}$ \\
\hline Power Transmit & $0 \mathrm{dBm}, 3 \mathrm{dBm}, 6 \mathrm{dBm}, 9 \mathrm{dBm}$ \\
\hline Distance from Antenna & $1 \mathrm{~m}$ \\
\hline Number of Samples & 1000 \\
\hline Temperature \& Humidity & 37.5 Celcius \\
\hline
\end{tabular}

The iron mesh box was wound by three layers of iron mesh in order to protect the signal from penetrating to the outside. The mesh type of metal is used to make sure there are air ventilation in the box so that the cells remain alive.

\section{RESUlt AND Discussion}

As a preliminary result, the reading of spec trum analyzer for certain frequency in and outside the iron mesh box is presented. Fig. 3 shows the setup frequency at $2.4 \mathrm{GHz}$ and $8 \mathrm{dBm} \mathrm{RF}$ power level on signal generator.

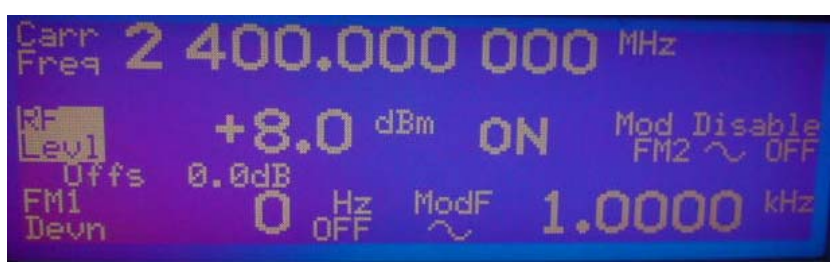

FIG 3: READING OF SIGNAL GENERATOR WHEN 8 DBM POWER IS RADIATED

A reading for a c ontrolled environment with background frequency of $2.4 \mathrm{GHz}$ which is considered the normal environment is obtained as shown in Fig. 4. The average signal power was approximately $-95 \mathrm{dBm}$ as reference reading in a normal environment equipped with WiFi facilities.

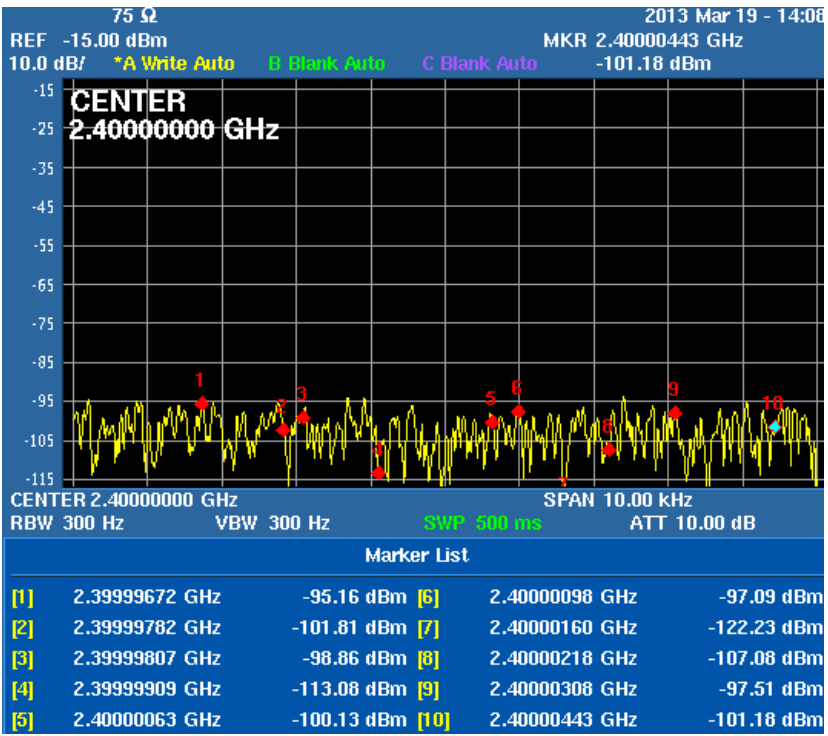

FIG 4: READING OF SPECTRUM ANALYZER FOR CONTROL ENVIRONMENT

After the signal generator is turned on, $8 \mathrm{dBm}$ of $\mathrm{RF}$ power is radiat ed with one meter distance between the spectrum analyzer. The power received is captured as $46.93 \mathrm{dBm}$ (refer marker number 5) as in Fig. 5.

The antenna was placed in the iron mesh box to measure the effectiveness of iron mesh box in absorbing the RF s ignal. Reading of spectrum analyzer outside of iron mesh box the shows signal power is dec rease at $88.28 \mathrm{dBm}$ (refer marker number 5) as in Fig. 6. This indicated that $88.11 \%$ of RF is absorbed by iron mesh box.

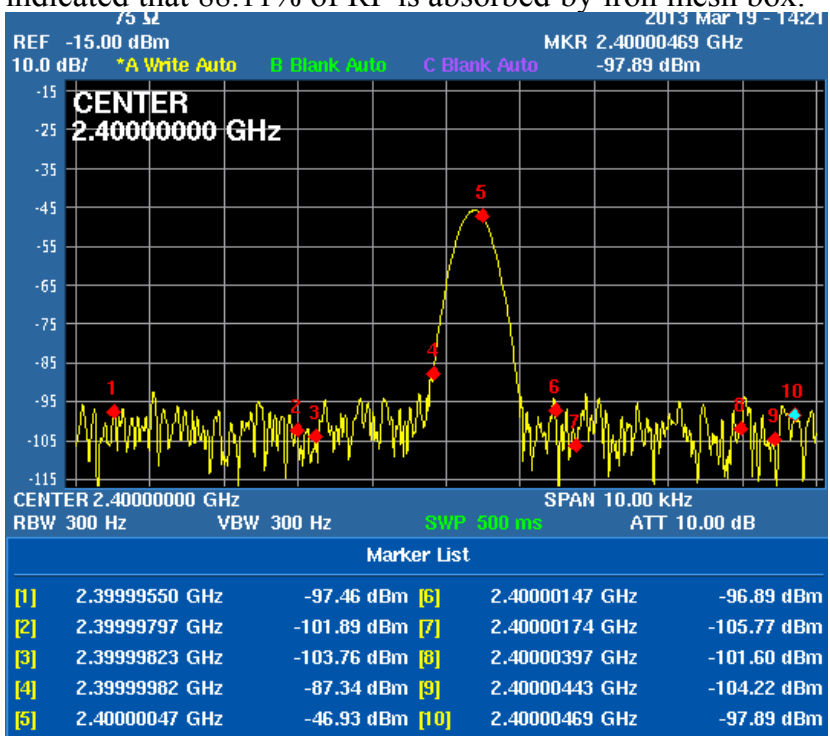

FIG 5: READING OF SPECTRUM ANALYZER WHEN 8 DBM POWER IS RADIATED FROM SIGNAL GENERATOR 


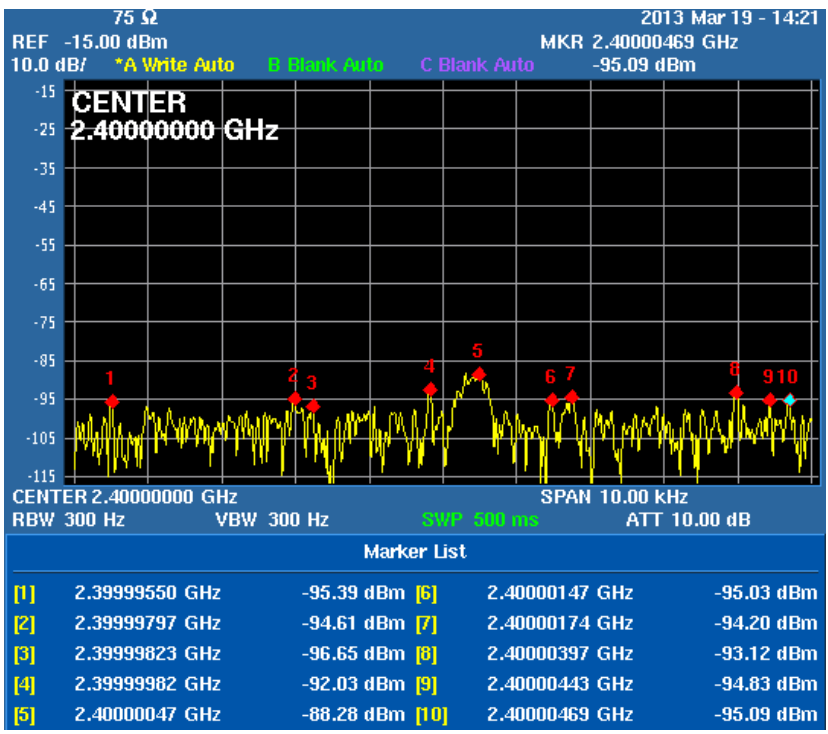

FIG. 6. READING OF SPECTRUM ANALYZER WHEN 8 DBM POWER WAS RADIATED FROM SIGNAL GENERATOR AND ABSORB BY IRON MESH BOX.

The data obtained is tabulated in Table II to compare the power radiated and received in the experiment.

TABLE II: PARAMETER USED IN THE EXPERIMENT

\begin{tabular}{|l|l|l|}
\hline $\begin{array}{l}\text { Power Transmit at } \\
\text { Signal Generator }\end{array}$ & $\begin{array}{l}\text { Power received } \\
\text { (Outside the Box) }\end{array}$ & $\begin{array}{l}\text { Power received } \\
\text { (Inside the Box) }\end{array}$ \\
\hline $8 \mathrm{dBm}$ & $-88.28 \mathrm{dBm}$ & $-46.93 \mathrm{dBm}$ \\
\hline
\end{tabular}

The results proved that the developed iron mesh box was able to block and absorb the radiated signal from signal generator about $88.11 \%$. The value captured was similar as the reference condition a $\mathrm{t}-95 \mathrm{dBm}$. Furthermore, the advantage of using mesh type material is the ability to allow the cells to breathe in inc ubator environment.

\section{CONCLUSION}

The success of the iron mesh box in absorbing almost $88.11 \%$ of RF sign als produced an environment of strength of the normal radiation for the cells wi thin the box. The strength of the signals measured in the incubator was reduced significantly by the mesh iron box and they are well within the normal power level permitted. More experiments will be conducted in the future using the emission of RF signal on animal culture cells and observations on the ch emicals produced by the cells during the test will be carried out.

\section{ACKNOWLEDGMENT}

The authors would like to acknowledge the Ministry of Higher Education, Malaysia for supporting the study by providing the research grant under FRGS 600-RMI/FRGS $5 / 3(41 / 2012)$

\section{REFERENCES}

[1] A. Rosen and H. D. Rosen, "The role of engineering principles in the medical utilization of electromagnetic energies: Examples," in Infrared, Millimeter and Terahertz Waves, 2008. IRMMW-THz 2008. 33rd International Conference on, 2008, pp. 1-1.

[2] J. C. Lin, "Safety standards for human exposure to radio frequency radiation and their biolo gical rationale," Microwave Magazine, IEEE, vol. 4, pp. 22-26, 2003.

[3] H. Suoto, M. Breckenridge, J. Hoppe, T. Purs che, and J. Beale, "Specific Absorption Rate (SAR) safety assessment for Wireless Network after Next (WNaN) radio antennas," in Wireless Information Technology and Systems (ICWITS), 2010 IEEE International Conference on, 2010, pp. 1-4.

[4] A. Ahmad, R. Ariffin, N. M. Noor, and M. A. Sagiruddin, "1.8 $\mathrm{GHz}$ Radio Frequency signal radiation effects on human health," in Control System, Computing and Engineering (ICCSCE), 2011 IEEE International Conference on, 2011, pp. 546-550.

[5] N. A. Fauzi, R. Ariffin, N. M. Noor, and I. S. Isa, "Comparisons on thermal effects Of $1.8 \mathrm{GHz}$ electromagnetic field exposure on Swiss Albino mice," in Control System, Computing and Engineering (ICCSCE), 2011 IEEE International Conference on, 2011, pp. 358363.

[6] N. H. Ishak, R. Ariffin, A. Ali, M. A. Sagiruddin, and F. M. T. Tawi, "Biological effects of WiFi electromagnetic radiation," in Control System, Computing and Engineering (ICCSCE), 2011 IEEE International Conference on, 2011, pp. 551-556.

[7] A. Rusnani, M. N. Norhayati, N. S. Siti, and M. Marina, "Microwave radiation effect \&\#x2014; a test on white mice," in $R F$ and Microwave Conference, 2008. RFM 2008. IEEE International, 2008, pp. 262-267.

[8] Y. Li, G. Manling, G. Jia, W. QingMeng, J. Xiaochi, and Y. Weili, "A Simulation for Effects of RF Electromagnetic Radiation from A Mobile Handset on Eyes Model Using The Finite-Difference TimeDomain Method," in Engineering in Medicine and Biology Society, 2007. EMBS 2007. 29th Annual International Conference of the IEEE, 2007, pp. 5294-5297.

[9] S. P. A. Bren, "Reviewing the RF safety issue in cellular telephones," Engineering in Medicine and Biology Magazine, IEEE, vol. 15, pp. 109-115, 1996. 